\title{
EHMTI-0168. Primary headache associated with sexual activity: fifteen new cases and therapeutic results
}

\author{
$\mathrm{K} Z$ Zhu $^{1 *}$, Y Huang ${ }^{2}$, J Chen $^{2}$ \\ From 4th European Headache and Migraine Trust International Congress: EHMTIC 2014 \\ Copenhagen, Denmark. 18-21 September 2014
}

\section{Introduction}

Primary headache associated with sexual activity (PHASA) is a rare benign headache disorder. To our knowledge, this is the first Chinese mainland fifteen cases.

\section{Aims}

To explore the clinical manifestations, diagnosis, treatment and prognostic features of PHASA.

\section{Methods}

Fifteen patients, 11 men, 4 women, from 26 to 56 years old(mean $42 \pm 11$ ), were prospectively analyzed over the past more than 7 years in our hospitals. The study was approved by our hospital Review Boardand and all of subjects have signed written informed consent.

\section{Results}

Their ages of onset were from 26 to 44 years old(mean $38 \pm 7$ ). For preemptive therapy, 8 patients had received indomethacin $(25-50 \mathrm{mg}$, intake $30-60 \mathrm{~min}$ prior to sexual activity). 7 patients reported good results and one limited success of this treatment and 4 patients had received sumatriptan $(50-100 \mathrm{mg}$, intake $30-60 \mathrm{~min}$ prior to sexual activity). 2 patients reported good results and remaining 2 had no response. They received ibuprofen for preemptive therapy complete success. Prophylactic treatment with propranolol was given in 8 patients. The dose was $60 \mathrm{mg}$ for propranolol. Six patients reported good results, two no success of propranolol prophylaxis. Other drug applied for prophylaxis was nimodipine in 4 patients, two success and two without success.

\section{Conclusions}

The patient who is diagnosed with PHASA should firstly receive indomethacin, or other drugs, sumatriptan, ibuprofen, is used for preemptive therapy if she/he can not get relief and(or)tolerate the adverse effects and should firstly receive propranolol, or other drug, nimodipine, is used for prophylaxis if she/he can not get relief and(or) tolerate the adverse effects.

No conflict of interest.

\section{Authors' details}

${ }^{1}$ Neurology, Panyu Hospital of Chinese Medicine, Guangzhou, China. ${ }^{2}$ Neurology, Guangdong No.2 provincial people's hospital, Guangzhou, China.

Published: 18 September 2014

doi:10.1186/1129-2377-15-S1-D77

Cite this article as: Zhu et al:: EHMTI-0168. Primary headache associated with sexual activity: fifteen new cases and therapeutic results. The Journal of Headache and Pain 2014 15(Suppl 1):D77.

${ }^{1}$ Neurology, Panyu Hospital of Chinese Medicine, Guangzhou, China

Full list of author information is available at the end of the article

(c) 2014 Zhu et al; licensee Springer. This is an Open Access article distributed under the terms of the Creative Commons Attribution License (http://creativecommons.org/licenses/by/2.0), which permits unrestricted use, distribution, and reproduction in any medium, provided the original work is properly cited. 